\title{
HHS ruling on Plan B introduces new risk for drugmakers
}

In December, US Department of Health and Human Services (HHS) Secretary Kathleen Sebelius made headlines when she nixed the decision by the US Food and Drug Administration (FDA) to make the emergency contraception pill Plan B One-Step available to girls 16 and younger without a prescription. Taking the long view, some fear that the secretary's decision to publicly overrule the FDA-an unprecedented action-could have a chilling effect on the development of other controversial medicines. "The message to the industry is clear," says Kenneth Kaitin, director of the Tufts Center for the Study of Drug Development in Boston. "If you're developing a drug or considering developing a new medicine in an area that might be politically charged, you should think again."

Plan B (levonorgestrel), first approved as a prescription medication in the US in 1999, sparked bitter wrangling four years later when the manufacturer, New Jersey's Barr Laboratories, requested that the pill be made available without a prescription. After several years of fierce debating, the agency approved the request for women 18 and older. A federal judge later ordered the FDA to lower the overthe-counter age to 17.

In February 2011, Israel-based Teva
Pharmaceuticals, the current manufacturer of Plan B One-Step, a single-pill form of the medication, asked that it be made available over the counter to all girls of childbearing age. The FDA was set to approve Teva's request. On 7 December, however, Sebelius directed FDA commissioner Margaret Hamburg to deny the appeal due to a lack of data on whether girls as young as 11 or 12 would know how to use the drug properly. A week later, the FDA also rejected a petition by the Center for Reproductive Rights, a New-York based advocacy group, to make the generic versions of Plan B (from manufacturers Watson Laboratories and Perrigo) available over the counter to girls in that same age bracket. In a letter to Sebelius, 14 Democratic senators expressed disappointment with her decision and asked the secretary to explain her rationale.

James Trussell, an economist at Princeton University in New Jersey who studies emergency contraception, expects that, going forward, manufacturers of oral contraceptives may be less inclined to ask that their products be made available over the counter. "This pretty much puts the kibosh on that," he says. However, he sees Sebelius's decision as a "one-off situation" that won't affect prescription drug development.

Similarly, the FDA's former deputy commissioner for medical and scientific affairs,
Scott Gottlieb, who is currently a fellow at the American Enterprise Institute, a Washington, DC-based think tank, argues that the decision won't have any far-reaching impact on the pharmaceutical industry. "You're not going to see the secretary weighing in on a whole bunch of products right now, and nothing that she did, in my view, establishes a new regulatory paradigm."

But others see the December bombshell as a potential game changer in the calculus of drug development. "Any company, when it comes to regulation-they want a predictable environment," says Kirsten Moore, president of the nonprofit advocacy group Reproductive Health Technologies Project in Washington, DC. "The way this drug review process was handled from the get-go has been unpredictable."

Moore fears that Sebelius's decision might open the door for future health secretaries to pull controversial medications such as the abortion pill mifepristone or the human papilloma vaccine off the market. The decision gives the impression that "policymakers can substitute their judgment for scientific analysis," she says. "What's to prevent any other policymaker from coming in and substituting their own judgment?"

Cassandra Willyard

\section{New NIH genetics center focuses its lens on exome, despite doubts}

Less than half of the more than 7,000 heritable diseases identified thus far have a known genetic origin. So, on 6 December, to help pinpoint the DNA glitches behind these disorders and thereby hasten diagnosis and drug development, the Bethesda, Marylandbased US National Human Genome Research Institute (NHGRI) and National Heart, Lung, and Blood Institute announced the funding of the Mendelian Disorders Genome Centers Program, part of a larger bundle of genomics grants totaling more than $\$ 400$ million toward projects it has also supported in the past.

The nearly $\$ 50$ million injected into the new Mendelian Disorders program over four years will go to four top genomics institutes in the US-the University of Washington in Seattle, Yale University in New Haven, Connecticut, and the joint genomics center from John Hopkins University in Baltimore, Maryland and the Baylor College of Medicine in Houston. These centers, which together already hold sequence data for around 12,000 individuals with more than 700 disorders, will add even more sequences, predominantly focusing on people's exons, the protein-encoding regions of the genome. The target diseases might run the gamut from more common diseases, such as heart muscle disorders, to rare diseases that only affect a few people, such as premature aging.

The center will sequence exons in lieu of full genomes because "a lot of the currently known Mendelian genetic variation is in the proteincoding regions," says Lu Wang, head of largescale sequencing at the NHGRI and director of the Mendelian Disorders Genome Centers. Exon sequencing is cheaper than wholegenome sequencing because only around 1-2\% of the genome encodes protein. Given the costs of sequencing, it makes the most economic sense to start there, Wang explains.

Increasingly, given technological advances, scientists are advocating whole-genome sequencing over exome sequencing. Although the latter only contains one-fiftieth of the sequence length analyzed, about the cost saving is only half, at around $\$ 2,500$ compared with $\$ 5,000$ for the whole genome. This is because it is more expensive and labor intensive to process genetic material for exome sequencing, according to David Bentley, vice president and chief scientist of San Diego's Illumina, a leading sequencing company. Additionally, exon sequencing produces lower-quality data, which means researchers need more DNA samples-an issue with often-rare Mendelian diseases for which a few samples have to go a long way. "If you're talking about rare samples or blood drops from children, these samples are precious," Bentley says.

Some scientists would rather see the Mendelian Disorders Genome Centers Program go after whole genomes from the get-go to capture the estimated $10 \%$ of genetic diseases that fall in the noncoding regions. "I wouldn't be surprised if the $\$ 1,000$ genome does indeed happen next year," says genomics veteran Orest Hurko, senior consultant at the Biologics Consulting Group, based in Alexandria, Virginia. "In that case, it's foolish to cut corners and just do the exons."

Hannah Waters 